\title{
Laboratory investigation of a bridge scour monitoring method using decentralized modal analysis
}

\author{
Muhammad Arslan Khan ${ }^{1 *}$, Daniel P. McCrum ${ }^{1}$, Luke J. Prendergast ${ }^{2}$, Eugene J. OBrien ${ }^{1}$, Paul \\ C. Fitzgerald ${ }^{1}$, Chul-Woo Kim ${ }^{3}$ \\ 1 School of Civil Engineering, University College Dublin, D04 V1W8 Belfield, Ireland; \\ muhammad.khan@ucdconnect.ie; daniel.mccrum@ucd.ie; eugene.obrien@ucd.ie; \\ paul.fitzgerald.3@ucdconnect.ie \\ 2 Department of Civil Engineering, Faculty of Engineering, University of Nottingham, Nottingham, \\ NG7 2RD, United Kingdom; luke.prendergast@nottingham.ac.uk \\ 3 Department of Civil and Earth Resources Engineering, Kyoto University, Kyoto, 615 8540, Japan; \\ kim.chulwoo.5u@kyoto-u.ac.jp \\ *Correspondence: muhammad.khan@ucdconnect.ie
}

\begin{abstract}
:
Scour is a significant issue for bridges worldwide that influences the global stiffness of bridge structures and hence alters the dynamic behavior of these systems. For the first time, this paper presents a new approach to detect bridge scour at shallow pad foundations, using a decentralized modal analysis approach through re-deployable accelerometers to extract modal information. A numerical model of a bridge with four simply supported spans on piers is created to test the approach. Scour is modelled as a reduction in foundation stiffness under a given pier. A passing half-car vehicle model is simulated to excite the bridge in phases of measurement to obtain segments of the mode shape using output-only modal analysis. Two points of the bridge are used to obtain modal amplitudes in each phase, which are combined to estimate the global mode shape. A damage indicator is postulated based on fitting curves to the mode shapes, using maximum likelihood, which can locate scour damage. The root mean square (RMS) difference between the healthy and scoured mode shape curves exhibits an almost linear increase with increasing foundation stiffness loss under scour. Experimental tests have been carried out on a scaled model bridge to validate the approach presented in this paper.
\end{abstract}

Keywords: Bridge health monitoring; structural dynamics; bridge scour damage; decentralized modal analysis; re-deployable sensors; vehicle-bridge interaction; laboratory-scaled bridge model

\section{INTRODUCTION}

Bridges with foundations in water can be affected by the washing away of soil, a concept termed scour erosion ${ }^{1}$. This phenomenon is responsible for a majority of bridge failures worldwide ${ }^{2-4}$ and causes significant economic and travel disruption ${ }^{5}$. Scour erosion causes a local reduction in soil elevation in the vicinity of bridge foundations, which affects the capacity and stiffness of the foundation system ${ }^{6}$. Losses in stiffness of the foundation system can lead to serviceability issues such as differential settlement, inclination of piers and abutments, and cracking in decks as well as partial or complete structural collapse ${ }^{7}$. The increased frequency of extreme weather events due to climate change is placing growing pressure on infrastructure networks worldwide, and many bridges on these networks are approaching the end of their design lives. There is an urgency among asset owners and operators to tackle these issues to ensure a sustainable future for these networks ${ }^{8}$.

The occurrence of scour around bridge foundations is typically managed by discrete monitoring and inspections. Visual inspections by asset management agencies remain the most common approach, which generally involves divers inspecting the condition of foundations and ranking bridges against rating criteria related to the perceived severity of the scour problem. The laborintensive nature of these types of inspection has 
inspired the development of sensor-based systems that can remotely detect and monitor scour evolution around bridge foundations. These systems include radar devices that measure changes in material properties and hence the location of the soil surface ${ }^{9}$, ${ }^{10}$, installed devices that float out of the soil when scour reaches their level ${ }^{11,12}$, and driven rod systems including magnetic sliding collars ${ }^{12}$ where physical sensors move along driven rods and rest on the riverbed within a scour hole. A full review of the performance of these types of sensor at detecting scour is available in Prendergast and Gavin ${ }^{13}$.

In recent years, online direct monitoring of changes in the structural response as a result of scour evolution has gained traction among researchers. Scour results in a stiffness change at foundations, which represents a change in the boundary conditions of the structure, and hence manifests as changes in modal properties ${ }^{14,15}$. Several researchers have investigated changes in modal properties as a way to detect and monitor scour erosion ${ }^{16}$. The majority of research has focused on identifying changes in natural frequency to detect scour. Prendergast et al. ${ }^{17}$ investigated the changes in natural frequency of a single pile affected by scour and proposed a Winkler-based spring-beam numerical model capable of tracking the frequency changes. The same authors later developed a vehicle-bridge-soil interaction $\operatorname{model}^{18}$ and investigated if changes in natural frequency due to scour of the central pier of a two-span integral bridge could be determined from vibrations in the structure under passing vehicles ${ }^{19}$. This approach was later extended to locating scour-related foundation stiffness losses, i.e. which pier or abutment is experiencing scour ${ }^{20}$, and investigating the influence of ambient temperature changes on the approach ${ }^{21}$. $\mathrm{Ju}^{22}$ developed a 3D numerical model to study how scour affects the natural frequency of a bridge in the presence of water-added mass, by incorporating soil-fluid-structure interaction. The presence of water lowers the natural frequencies of a structure compared to the case where there is no water, and the effect of scour is to reduce the natural frequencies. However, a non-smooth frequency change is observed due to non-uniform foundation elements and layered soils. Kong and Cai ${ }^{23}$ studied the effect of scour on the response of a bridge with traversing vehicles, in the presence of wave loads. Results suggested that scour has a significant influence on the lower frequencies of a bridge pile. Since the entire bridge is affected by scour, it is suggested that the response of the deck near the supports or the response of passing vehicles can be used to detect scour presence. Bao et al. ${ }^{24}$ studied frequency-based scour detection from the perspective of identifying the physical meaning of predominant natural frequency, optimal location of sensors, and the effect of scour hole shape ${ }^{25}$. They conclude that natural frequency reduces with scour progression, but the frequency values differ depending on whether the sour hole is symmetrical or unsymmetrical, due to differences in the soil constraints. Chen et al. ${ }^{26}$ identified various modal frequencies of a cable-stayed bridge, developed a numerical model of the system, optimized the model boundary conditions, and used the model to estimate the scour condition at a pier based on measured and predicted frequencies.

In addition to frequency-based scour detection, several researchers have investigated the monitoring of other dynamic parameters to infer the presence of scour. Xiong et al. ${ }^{27}$ studied four dynamic indicators for scour detection in cable-stayed bridges, namely frequency, modal assurance criterion, mode shape curvature, and flexibility-based deflection. They suggest that flexibility-based deflection can be a sensitive indicator of scour as long as an accurate reference numerical model of the bridge is available. Furthermore, the use of mode shape curvature is not deemed practical due to the high number of sensors required. Natural frequency, while sensitive and practical to measure, can only qualitatively indicate scour presence due to its sensitivity to other damage that may be present in the structure. Elsaid and Seracino ${ }^{28}$ also investigated mode shape curvature and flexibility-based deflection as well as flexibilitybased curvature for detecting scour on a scaled model of a coastal bridge. Each of these indicators showed promise for scour detection. However, this study simply modelled scour as an increase in pile effective length and omitted any soil-structure interaction. Foti and Sabia ${ }^{29}$ analysed scour development on a five-span bridge by monitoring the asymmetric dynamic behaviour of a scoured pier, using an array of accelerometers along the foundation mat. Scour was detectable by analysing the covariance of measured accelerations along the foundation but was not quantifiable. Malekjafarian et al. ${ }^{6}$ proposed a mode shape-based scour monitoring method for bridges with shallow foundations, based on measuring changes in the modal amplitude at a given pier relative to the mean of the amplitudes at remaining piers as detected from 
output-only modal analysis. Using sensors located at each pier, the mean-normalised mode shape exhibited sensitivity to scour-related foundation stiffness loss at given piers. The method was experimentally validated on a laboratory-scale bridge.

To address the shortcomings associated with frequency-based damage detection, modal estimation techniques using bridge accelerations have received increasing attention over the past two decades for effective health monitoring and parameter identification ${ }^{30-33}$. Obtaining mode shapes from modal testing ${ }^{31}$ or from output-only modal methods ${ }^{33}$ typically suffer the common drawback of requiring large numbers of sensors installed on a bridge to obtain a full picture of the modal behaviour, which can make these systems expensive and difficult to maintain. To overcome these challenges, decentralized and multi-setup approaches for modal analysis have been proposed for damage detection techniques ${ }^{34-41}$, that use independent groups of data with overlapping nodes to capture local spatial information in stitch-able segments $^{39}$, or reference-based multi-setup stochastic subspace identification algorithms $\mathrm{s}^{41,42}$. These approaches have been successfully implemented and tested both in numerical as well as field environments. For example, Sim et al. ${ }^{39}$ analysed different network topologies for the decentralized approaches and study the effect of changing overlapping nodes on the accuracy of the estimated global mode shapes, and Dohler et al. ${ }^{42}$ computed statistical uncertainties and covariance mode shapes derived using a multi-setup subspace system identification algorithm and applied the approach on actual bridge vibration data.

Indirect health monitoring methods have come to the fore recently, which aim to estimate bridge dynamic properties using responses measured from moving sensors such as instrumented vehicles, reducing the sensor burden ${ }^{43}, 44$. Indirect monitoring using passing vehicles has shown promise at detecting changes in natural frequencies ${ }^{45-47}$, damping $^{48}$ and road surface roughness of bridges ${ }^{49}$, 50. These methods rely on modal identification approaches such as Short Time Frequency Domain Decomposition (STFDD), which was used to estimate bridge mode shapes from multiple vehicle acceleration measurements in a recent study ${ }^{51,52}$. The method works by measuring segments of mode shapes from signals arising in a vehicle crossing a bridge, using Frequency Domain Decomposition
$(\mathrm{FDD})^{53}$, which are combined together using common points between neighboring segments ${ }^{35}$, 36,39 . Despite showing promise, the indirect STFDD method is critically influenced by the vehicle velocity and has been shown to only be effective when the vehicle is travelling at unrealistically slow velocities.

In this paper, a novel approach to bridge scour detection is proposed using a decentralized approach based on re-deployable accelerometers that is verified in a laboratory environment. The approach does not require a reference model for detecting and locating damage, improving on the limitations of previous damage-detection methods. While not explicitly modelled, the sensors could be deployed using Unmanned Arial Vehicles (UAVs), which would land, collect data, and move to the next point on a bridge, in a sequence of operations. This would enable data acquisition to be carried out over the full length of a bridge with limited sensor requirements. It is envisaged that a given structure would remain operational during data acquisition, therefore forced accelerations due to passing vehicles are measured during each data acquisition phase, which has the added advantage of assessing the performance of the approach when natural vehicle-related variability is incorporated. A variety of modal estimation methods exist and there is significant variability in the accuracy of resulting modal properties depending on which method is adopted. Due to its simplicity and ease of execution with reasonable results, the FDD technique is used in this paper to extract modal information from the measured bridge accelerations. The trade-off with ease of execution lies with the possible introduction of errors in the estimated modal parameters. FDD works by extracting segments of the mode shape, which can subsequently be combined to form a global mode shape. This approach is tested using only two accelerometers in this paper, which are considered as being deployed to various points along a bridge over time. Both numerical modelling and experimental testing are performed in the present work. A one-dimensional half-car vehicle model is simulated to cross a four span bridge $\operatorname{model}^{54,55}$ with three piers having sprung masses and representative foundation stiffness ${ }^{56}$. A class ' $A$ ' road profile is included on the bridge ${ }^{57}$. In each phase of simulated measurement, bridge accelerations are calculated at two points on the bridge (for a given number of vehicle passages) and a portion of the mode shape is estimated. The global mode shape for each case, 
along with a fitted curve and mode shape gradient, are used to detect the location of scour-related foundation stiffness loss, without the requirement of a prior knowledge of a healthy reference mode shape. The root mean square (RMS) difference is used to estimate the severity of the scour problem relative to the theoretical healthy mode shape. The proposed approach is validated using a laboratoryscaled bridge. The results from experimental tests demonstrate the effectiveness of the decentralized approach at detecting the presence and location of scour. The method may prove useful for rapid postflood bridge evaluation on a network.

\section{NUMERICAL ANALYSIS}

\subsection{Bridge Model}

A multi-span single-lane bridge is simulated in this paper as a 1D finite element (FE) model ${ }^{55}$ using MATLAB. The bridge model comprises four $20 \mathrm{~m}$ long, simply supported spans, each modelled using 20 Euler-Bernoulli beam elements ${ }^{58}$, with four degrees of freedom (DOF) (see Figure 1). The beginning and end of the bridge rests on undeformable supports, modelled as pins and rollers, whereas the internal connections are modeled as hinged supports, resting on deformable piers. The presence of potential eccentricities at the internal supports due to the pin and roller arrangement are not considered, therefore potential bending moments in the piers are not modelled. The piers are instead idealized to only enable vertical motion, which may introduce minor errors into the model. Three internal piers, modeled as single-DOF sprung masses (with stiffness, $k_{\mathrm{pier}, i}$ and mass, $\left.m_{\mathrm{pier}, i}\right)$, are assumed to rest on shallow pad foundations, modelled using a foundation spring $k_{\mathrm{f}, i}\left(i=1,2, \ldots N_{p}\right)$, where $N_{p}$ is the number of piers. The properties of the foundation springs are derived to correspond to a $4 \mathrm{~m} \times 2 \mathrm{~m}$ shallow pad foundation in contact with a uniform medium dense sand deposit ${ }^{44}, 59$, using the expression in Eq. $1^{60}$ :

$$
k_{f}=\frac{G B}{1-v}\left[1.55\left(\frac{L}{B}\right)^{0.75}+0.8\right]
$$

where $G$ is the soil shear modulus $(\mathrm{kPa}), v$ is the Poisson's ratio, $L$ and $B$ are the foundation length (m) and width (m), respectively. The soil shear modulus is calculated from the elastic modulus using the expression $G=(1 / 2) E /(1+v)$, where $E=100,000 \mathrm{kPa}^{59}$. Eq. 1 is semi-empirical and more information on similar expressions are available in Pais and Kausel, and Mylonakis et al. 61, 62. The geometric and material properties of the bridge and foundation are provided in Table 1.

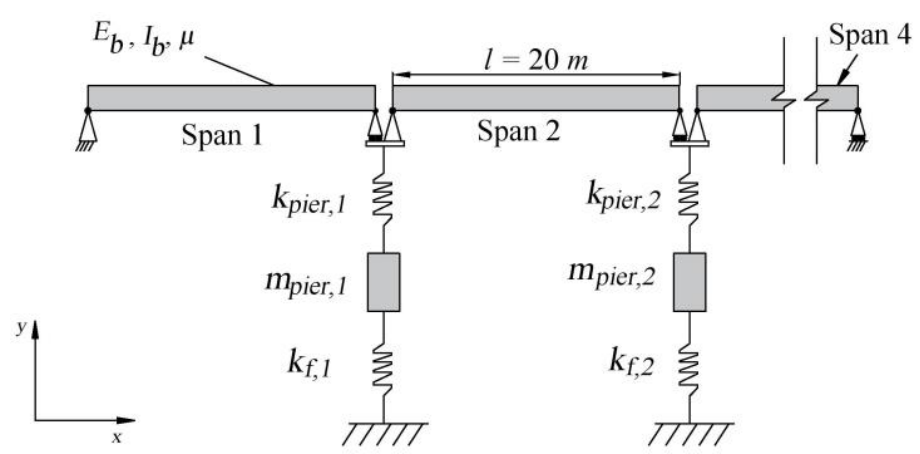

Figure 1 Schematic of the modelled bridge.

Table 1

Geometric and material properties of the bridge model.

\begin{tabular}{lll}
\hline Bridge property & Notation & Value \\
\hline Number of DOFs & $N$ & 171 \\
Bridge width & $b$ & $4 \mathrm{~m}$ \\
Young's modulus & $E$ & $35 \times 10^{9} \mathrm{~N} / \mathrm{m}^{2}$ \\
$2^{\text {nd }}$ moment of area & $I$ & $0.33 \mathrm{~m}^{4}$ \\
Mass per unit length & $\mu$ & $9600 \mathrm{~kg} / \mathrm{m}$ \\
Pier length & $l_{\text {pier }}$ & $7 \mathrm{~m}$ \\
Pier width & $b_{\text {pier }}$ & $2.5 \mathrm{~m}$ \\
Pier depth & $d_{\text {pier }}$ & $1 \mathrm{~m}$ \\
Foundation spring & $k_{f, i}$ & $344.12 \times 10^{6}$ \\
stiffness & & $\mathrm{N} / \mathrm{m}$ \\
\hline
\end{tabular}


A class ' $A$ ' road surface profile is randomly generated $^{57}$ according to the ISO standard ${ }^{63}$. An approach length of $100 \mathrm{~m}$ is used to ensure the equilibrium of vehicle dynamic behavior when it enters the bridge. The dynamic response of the bridge due to the time varying moving forces are given by a system of equations at each time step:

$$
M_{b} \ddot{y}_{b}+C_{b} \dot{y}_{b}+K_{b} y_{b}=f_{\text {int }}
$$

where $M_{b}, C_{b}$ and $K_{b}$ are bridge mass, damping and stiffness matrices, respectively, and $\ddot{y}_{b}, \dot{y}_{b}$ and $y_{b}$ are the vectors of bridge accelerations, velocities and displacements for each DOF, respectively. $f_{\text {int }}$ is a vector representing the interaction forces between the bridge and the vehicle ${ }^{55}$ as it traverses the bridge.

\subsection{Vehicle Model}

A half-car model, shown in Figure 2, is employed to represent a 2 -axle vehicle ${ }^{54,64}$. The vehicle has four DOFs, namely body mass translation $\left(y_{s}\right)$, body pitch $(\theta)$, and two axle mass translations $\left(y_{u, i}\right)$. The axle masses are represented by $m_{u, 1}$ and $m_{u, 2}$, respectively and are connected to the body mass $\left(m_{s}\right)$ through springs with linear stiffness $\left(k_{s, i}\right)$ and viscous damping coefficients $\left(C_{s, i}\right)$. The vehicle makes contact with the road surface though tire springs of linear stiffness $\left(k_{t, i}\right)^{54}$. In this study, a series of vehicles are programmed to cross the bridge and Table 2 shows the mechanical properties adopted for all vehicles ${ }^{48,54,64}$. The body mass and velocity is varied for each vehicle to simulate the expected variability in traffic loading. A Weigh-InMotion (WIM) database from Illinois, provided by the U.S. Federal Highway Administration's LongTerm Pavement Performance program ${ }^{65,66}$, is used to develop a distribution of representative vehicle masses and velocities. A population of 2-axle vehicles, with axle spacings varying between $5 \mathrm{~m}$ and $7 \mathrm{~m}$, is extracted from the database. For each vehicle run in this paper, the body mass and vehicle velocity are chosen randomly from this population of vehicles, therefore each simulated vehicle crossing the bridge has a different mass and velocity to remain in keeping with reality.

Equilibrium of forces is used to develop the equation of motion for the vehicle in terms of the degrees of freedom:

$$
M_{v} \ddot{y}_{v}+C_{v} \dot{y}_{v}+K_{v} y_{v}=f_{v}
$$

where $M_{v}, C_{v}$ and $K_{v}$ are the mass, damping and stiffness matrices of the vehicle respectively, and $\ddot{y}_{v}$, $\dot{y}_{v}$ and $y_{v}$ are the vectors of vehicle accelerations, velocities and displacements, respectively. The vector $f_{v}$ represents the time-varying interaction forces applied to the vehicle DOFs by the road profile and the bridge displacements. In modelling terms, the bridge and vehicle models are coupled ${ }^{55}$ and the global equation of motion is formed by combining Equations 2 and 3:

$$
M_{g} \ddot{u}+C_{g} \dot{u}+K_{g} u=F
$$

where $M_{g}$ and $C_{g}$ are the coupled mass and damping matrices, respectively. $K_{g}$ is the timevarying coupled stiffness matrix that depends on the bridge static displacements due to the vehicle. $F$ is the system force matrix, and $\ddot{u}, \dot{u}$ and $u$ are the vectors of accelerations, velocities, and displacements of the global system, respectively. The equation of the coupled system is solved in MATLAB using the Wilson-Theta integration scheme $^{67}$.

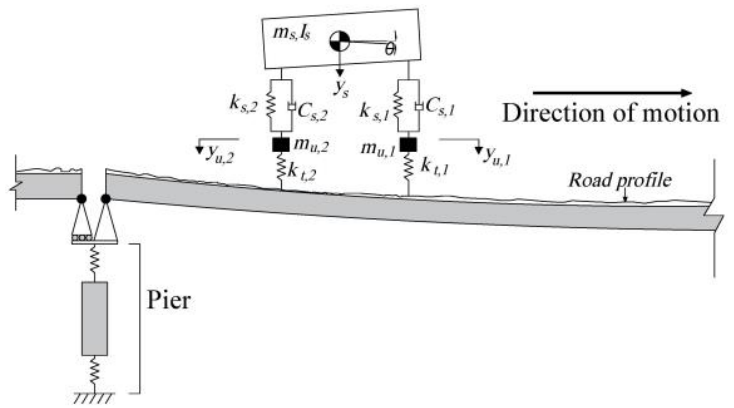

Figure 2 A section of a half-car model with a road profile on the bridge.

Table 2

Properties of the half-car model.

\begin{tabular}{lll}
\hline Vehicle property & Notation & Value \\
\hline \multirow{2}{*}{ Axle masses } & $m_{u, 1}$ & $750 \mathrm{~kg}$ \\
& $m_{u, 2}$ & $1100 \mathrm{~kg}$ \\
Tyre stiffnesses & $k_{t, 1}$ & $1.75 \times 10^{6} \mathrm{~N} / \mathrm{m}$ \\
& $k_{t, 2}$ & $3.5 \times 10^{6} \mathrm{~N} / \mathrm{m}$ \\
Suspension & $k_{s, 1}$ & $0.5 \times 10^{6} \mathrm{~N} / \mathrm{m}$ \\
stiffnesses & $k_{s, 2}$ & $1.0 \times 10^{6} \mathrm{~N} / \mathrm{m}$ \\
Suspension & $C_{s, 1}$ & $1.0 \times 10^{4} \mathrm{~N} \mathrm{~s} / \mathrm{m}$ \\
damping & $C_{s, 2}$ & $15 \times 10^{3} \mathrm{Ns} / \mathrm{m}$ \\
\hline
\end{tabular}

\section{DECENTRALIZED APPROACH TO ESTIMATE BRIDGE MODE SHAPE}

The decentralized concept of using re-deployable sensors to estimate mode shapes requires the scaling and stitching together of mode shape segments calculated at discrete sensor locations ${ }^{35,37,39}$. A pair of accelerometers are placed at discrete points along the bridge and calculate the modal response at their 
location due to vehicles passing along the bridge. These sensors are moved to various points over time (as could be undertaken using UAVs or otherwise). The modal response (mode shape amplitude) corresponding to a given frequency is estimated from the discrete accelerations measured at these locations using FDD. This is achieved using Singular Value Decomposition, which is applied to decompose the spectral density matrix, $\hat{G}\left(j \omega_{i}\right)$, for each frequency $i$ of the response $\mathrm{e}^{53}$ :

$$
\widehat{G}\left(j \omega_{i}\right)=U_{i} S_{i} U_{i}^{H}
$$

where, $U_{i}$ is the unitary matrix of singular vectors, $S_{i}$ is a diagonal matrix containing singular values and $H$ denotes the complex conjugate of the matrix. The singular vectors provide the mode shape amplitudes corresponding to a selected frequency.
The concept is illustrated in Figure 3 where two accelerometers (Acc 1 and Acc 2) are moved along the bridge in eight phases to build the global mode shape(s). In each phase, a vector of mode shape amplitudes $\left[\varphi_{l i}, \varphi_{r i}\right]$ corresponding to a segment of a mode shape is extracted. These segments are then rescaled and stitched together using a common location between neighboring segments. One accelerometer remains fixed while the other is moved to the next location to maintain continuity. The global mode shape $\left(\emptyset_{\psi i}\right)$ for the $i^{t h}$ frequency, using $r$ segments $\left[\psi_{1}, \psi_{2}, \ldots \psi_{r}\right]$, can be calculated by:

$$
\emptyset_{\psi}^{i}=\bigcup_{s=1}^{r} R_{s} \psi_{s}
$$

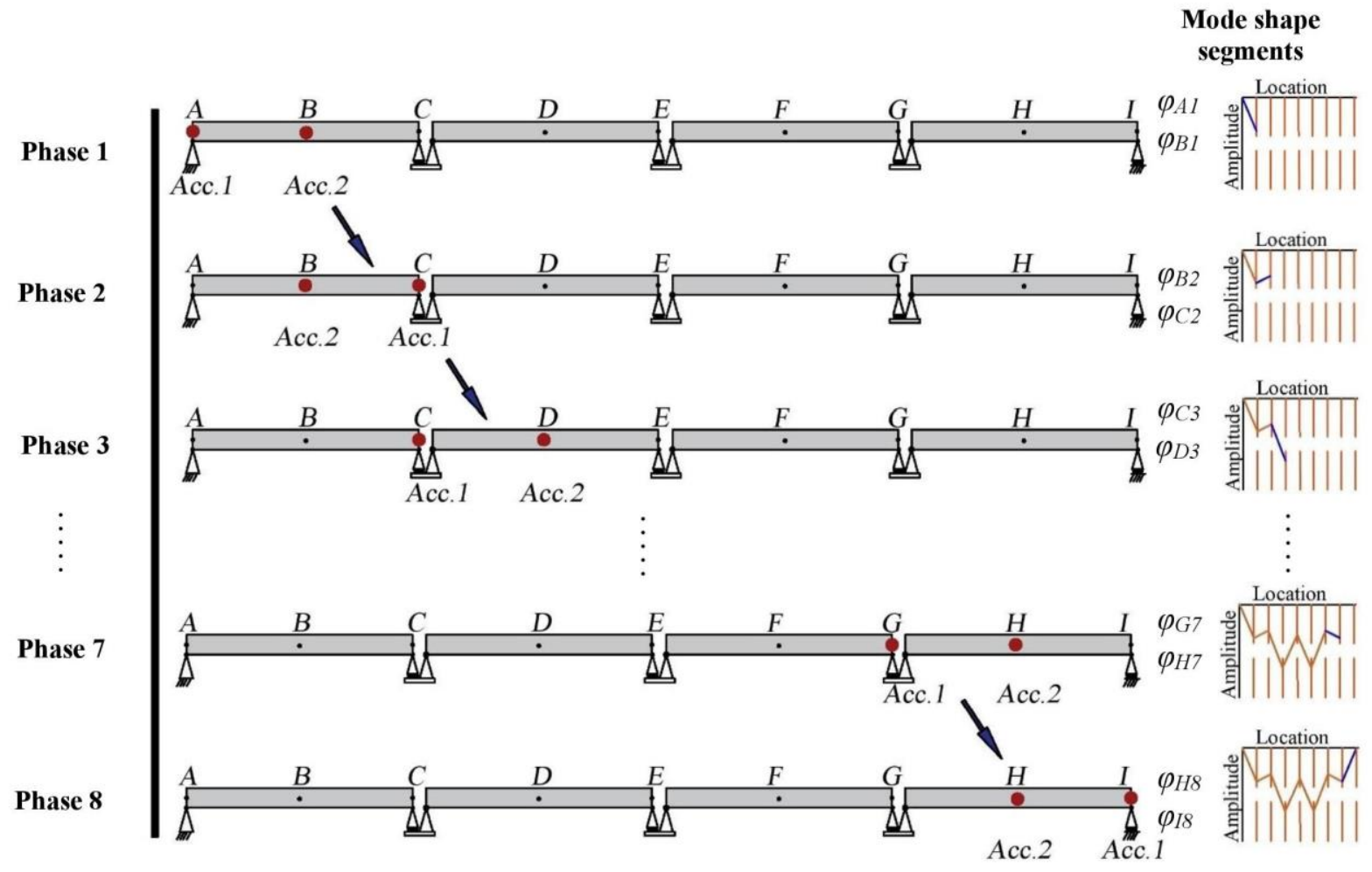

Figure 3 Example of the proposed re-deployable accelerometers concept.

In the numerical analysis in this paper, the nodal accelerations simulated in the vehicle-bridge interaction model are used to represent the 'accelerometers', deployed at various points. The bridge length is divided into 8 segments (corresponding to sensor placement phases) - each having a length of $10 \mathrm{~m}$ (half a span length). The accelerometer locations are chosen as the supports and the midspan of each simply supported beam, as illustrated in Figure 3. For a given placement of two sensors (i.e. one phase), a single vehicle is modelled to cross the bridge, with the parameters chosen from the population of vehicles as described previously. A segment of a given mode shape is derived for each phase from the nodal accelerations generated due to the vehicle crossing, with 2 seconds of free vibration assumed after the vehicle departs the bridge. To include measurement error, random noise is added to the acceleration signals ${ }^{48}$ with zero mean and a standard deviation ranging between $3.5 \%$ and $8.5 \%$, depending on the gross vehicle weights. These percentages are based on a sample of field 
measurements and engineering judgement to incorporate the variability of signal to noise ratio with respect to the amplitude of the signal.

A demonstration of the decentralized approach is shown in Figure 4. Figure 4(a) shows the discrete mode shape amplitudes (connected by straight lines) for the first mode of the 4-span bridge, as developed by moving two accelerometers along the bridge model in phases. Also shown in this plot is the theoretical first mode shape amplitudes at the same points, as extracted from an eigenvalue analysis on the model mass and stiffness matrices ${ }^{68}$. Figure $4(\mathrm{~b})$ shows the same information but for the second mode shape of the bridge. The estimated and theoretical mode shapes agree well, with a Modal Assurance Criterion (MAC) analysis giving values of 0.9985 and 0.9976 for the first and second modes, respectively. This suggests that the re-deployable approach using single overlapping sensor location performs well and is not significantly affected by variation in vehicle properties.

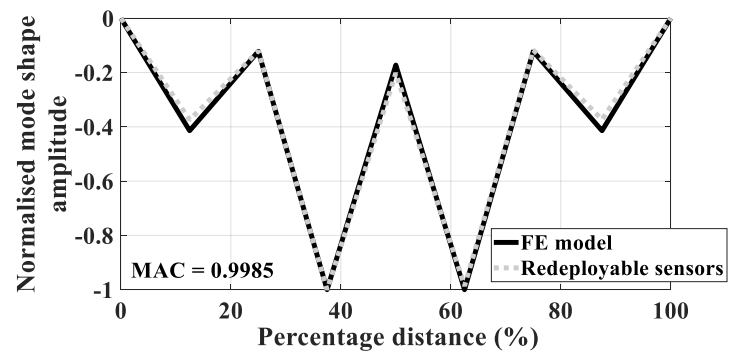

(a)

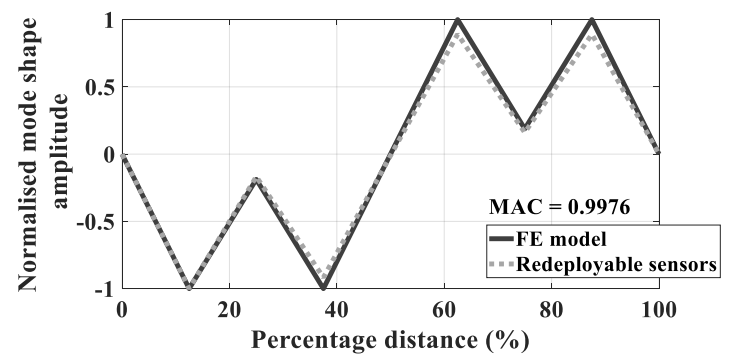

(b)

Figure 4 Estimated (using re-deployable sensors approach) and theoretical mode shapes (Eigenvalue mode shapes of FE model): (a) the first, and

(b) the second mode shape.

\section{SCOUR DETECTION APPROACH}

In this paper, the damage due to scour occurrence is considered as a loss in vertical foundation stiffness in a shallow pad at a given pier. While other damage mechanisms are not explicitly considered (that may or may not be present in the bridge structure), the assumption underlying scour damage is that this typically occurs reasonably quickly, for example, during a discrete flood event. This would lead to a change in the modal properties before and after such an event. Other damage, for example corrosion or bearing damage tends to occur more slowly. However, it should be noted that if damage leads to a change in the modal properties, this can be used to trigger a manual inspection, which will identify the source of damage, and so is still of practical use for a bridge manager.

The mechanism for scour-related foundation stiffness loss is based on the overburden and straindependency of soil shear modulus, $G$. This is a depth-dependent parameter and typically varies nonlinearly with mean stress level, so a reduction in soil elevation (and overburden stress) due to scour, lowers the $G$ value at the formation level of the foundation. Recent experimental tests on laterally loaded piles have revealed how the strength and stiffness of soil depend on the shape of the scour hole, highlighting the sensitivity of these properties to the amount of overburden removed ${ }^{25}$. Additionally, scour is considered in this paper to undermine a shallow foundation, reducing the soilfoundation contact area, which increases the stress in the remaining soil. Increasing the stress leads to an increase in strain, according to the nonlinear stress-strain behavior of soil, and $G$ typically reduces with strain $^{69}$. Therefore, the combined action of reducing the soil elevation and undermining the shallow foundation, can lead to significant reductions in vertical foundation stiffness, in accordance with Eq. 1. Many previous works have focused on scour effects on piled bridges, where the mechanism for scour reduces the lateral stiffness and capacity of piled foundations ${ }^{19}$, $20,28,29,70$. In the present work, the focus is on bridges with shallow foundations, where the vertical stiffness is affected by scour undermining the foundation, a mechanism that has received much less attention in previous literature.

Two scour damage cases are considered in this work, $25 \%$ and $45 \%$ foundation stiffness reductions at two piers. Table 3 shows the assumed geometrical and material properties for these two scour cases. For the case of $25 \%$ foundation stiffness loss, this could correspond, for example, to a scour hole undermining a pad such that it reduces the soilfoundation contact area by $\approx 30 \%$, with a corresponding reduction in $G$ of $\approx 9 \%{ }^{69}$. For the $45 \%$ foundation stiffness reduction, this could correspond (for example) to a reduction in soil-foundation contact area of $\approx 50 \%$ and a reduction in $G$ of $\approx 20 \%$.

The following text describes the scour detection approach investigated in this paper. Mode shapes are derived from the re-deployed sensors for scour at the central pier and the right-hand side pier (refer to Figure 3) for both scour cases in Table 3, using the numerical model. To assess the repeatability of the analysis, a representative set of vehicle runs are used 
Table 3

Scour modelling parameters.

\begin{tabular}{|c|c|c|c|c|}
\hline Case & $\begin{array}{l}\text { G } \\
\text { (MPa) }\end{array}$ & $\begin{array}{l}\mathbf{B}^{\prime} \\
(\mathbf{m})\end{array}$ & $\begin{array}{l}\mathbf{L}^{\prime} \\
(\mathbf{m})\end{array}$ & $\begin{array}{l}\mathbf{k}_{\mathbf{f}} \\
(\mathrm{kN} / \mathrm{m})\end{array}$ \\
\hline No Scour & 45.45 & 2 & 4 & 344120 \\
\hline $\begin{array}{l}\text { Case } 1 \\
(25 \% \text { loss })\end{array}$ & 41.4 & 1.8 & 3.1 & 258955 \\
\hline $\begin{array}{l}\text { Case } 2 \\
(45 \% \text { loss) }\end{array}$ & 36.4 & 1.4 & 2.8 & 192701 \\
\hline
\end{tabular}

to derive healthy and damaged mode shapes. Fifty first mode shape estimates are developed for the healthy case, and for each of four damage cases. The damage cases consist of $25 \%$ and $45 \%$ foundation stiffness loss at each of two piers, the second (central) and the third (right) piers. Since eight vehicle runs are required to estimate a single mode shape using the re-deployable sensors, this equates to a total of $400(=50 \times 8)$ vehicle runs, with variable body masses and velocities, for the healthy case and for each scour case. Figure 5 presents the results of the analysis. Figure 5(a) shows the first mode shapes for the healthy case and scoured cases at the central pier, and Figure 5(b) shows the same information for scour at the third pier. The shaded region for each mode shape shows the mean \pm one standard deviation at each location of the inferred mode shape, based on the fifty vehicle passes in each case. The vertical lines in Figure 5 show the locations of the piers, with dashed line denoting healthy, and dotted line denoting scour locations. It can be observed that the reduction in foundation stiffness at the central pier, Figure 5(a), and at the right-hand side pier, Figure 5(b), reduces the mode shape amplitude at those points, changing the overall shape of the first mode shape. It can be seen in Figure 5(a) and (b) that the shaded regions of the modal amplitudes do not overlap with each other, when plotting the mean \pm one standard deviation of the measured dataset. It should be acknowledged that if the entire population of the distribution were considered, some overlap would undoubtedly occur, which would mask the presence of scour. This is a wider issue with many damage detection approaches and has been studied in other works ${ }^{71}$. Plotting the mean \pm one standard deviation accounts for almost $70 \%$ of the total population.

The change in the mode shape due to scour can potentially assist in locating scour damage. A damage indicator to locate scour is postulated based on fitting a polynomial curve to the estimated first mode shape amplitudes ${ }^{72}$, and identifying changes in these fitted curves between healthy and scoured conditions. To decide on the order of curve to be adopted, a maximum likelihood analysis ${ }^{73}$ is carried out and the Akaike Information Criterion (AIC) ${ }^{74}$ is calculated for several polynomials of increasing order. The AIC considers the trade-off between goodness of fit and complexity (order) of the polynomial used. Low order polynomials and good fits both reduce the AIC value. The curve with the lowest AIC is considered as the most appropriate fit for a given set of modal amplitudes (given damage case in this paper). AIC is calculated as twice the difference between the number of unknown variables and the maximum loglikelihood for each $\mathrm{fit}^{74}$. The number of unknown variables for each case equates to the degree of the curve fit, e.g. a secondorder polynomial has two unknowns, a third-order has three unknowns, etc. Table 4 provides the values of likelihood and AIC for the fitted mode shapes from each scour condition and degree of polynomial fit, up to $7^{\text {th }}$ order. It can be observed that the most appropriate degree of fit for each damage case is different.

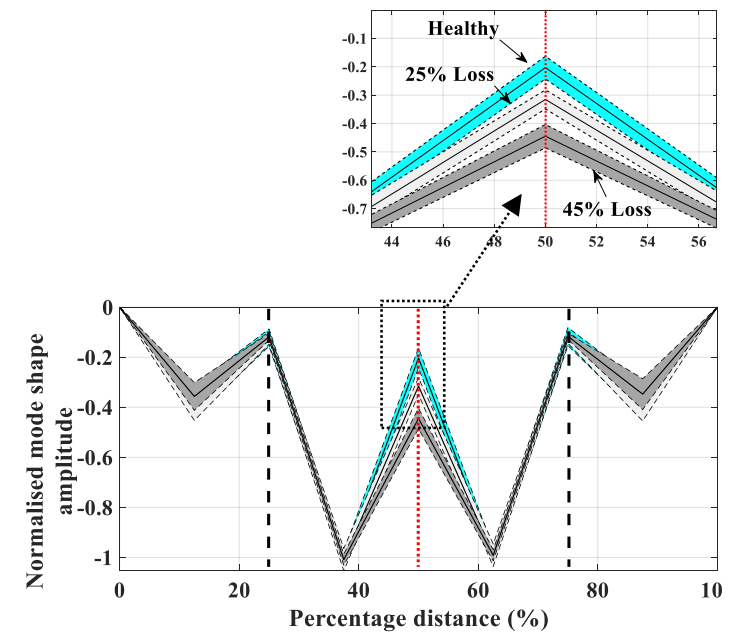

(a)

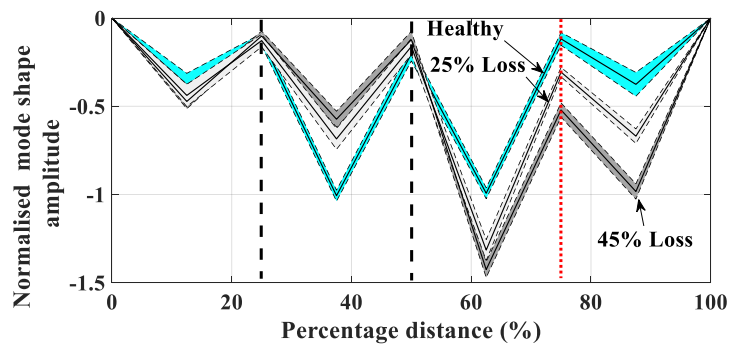

(b)

Figure 5 The first mode shape with the scour effect: (a) scour at pier 2, and (b) scour at pier 3.

However, both $3^{\text {rd }}$ and $4^{\text {th }}$ degree polynomials have good AIC scores for all cases. In order to allow comparison between cases, the same order of 
polynomial is desirable for all cases and the $4^{\text {th }}$ order is chosen here for this purpose.

Figure 6 presents the results of fitting $4^{\text {th }}$ degree polynomials to the modal amplitudes of Figure 5. Fourth degree polynomials are also fitted to the envelope of the data, i.e., to the mean \pm one standard deviation of the estimated modal amplitudes. It can be seen, in Figure 6(a) in particular, that fitting polynomials removes much of the detail evident in Figure 5. However, the influence of damage is perhaps more obvious, with increased amplitude at scoured piers. The range of results indicates that 50 estimates of mode shapes should be enough to detect $25 \%$ stiffness loss at the central pier, and much less at the third pier. The maximum change in peak value occurs at the location of the scoured pier in each case, and the change in peak is larger for higher increases in foundation stiffness loss associated with scour. For scour at the central pier in Figure 6(a), the mean change in peak value for $25 \%$ and $45 \%$ foundation stiffness loss is $7.2 \%$ and $16.8 \%$, respectively. For scour at the right-hand pier in Figure 6(b), the mean change in peak value for $25 \%$ and $45 \%$ foundation stiffness loss is $67.6 \%$ and $125.2 \%$, respectively. This damage indicator provides an impartially objective metric, that is not dependent on any underlying parameters, as compared to using the mode shape amplitudes directly, and offers a way to locate scour without having prior knowledge of structural behaviour.

Table 4

The maximum likelihood and AIC values for each bridge scour case.

\begin{tabular}{|c|c|c|c|c|c|c|c|c|c|c|c|c|c|}
\hline \multirow[b]{3}{*}{ Cases } & \multicolumn{6}{|c|}{ Maximum Likelihood } & \multicolumn{6}{|c|}{ AIC Value } & \multirow{3}{*}{ 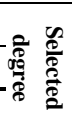 } \\
\hline & \multicolumn{6}{|c|}{ Degree of polynomial fit } & \multicolumn{6}{|c|}{ Degree of polynomial fit } & \\
\hline & $2^{\text {nd }}$ & $3^{\text {rd }}$ & $4^{\text {th }}$ & $5^{\text {th }}$ & $6^{\text {th }}$ & $7^{\text {th }}$ & $2^{\text {nd }}$ & $3^{\text {rd }}$ & $4^{\text {th }}$ & $5^{\text {th }}$ & $6^{\text {th }}$ & $7^{\text {th }}$ & \\
\hline Healthy & 0.03 & 0.03 & 0.04 & 0.04 & 0.15 & 0.15 & 11.1 & 13.1 & 14.7 & 16.7 & 15.7 & 17.7 & $2^{\text {nd }}$ \\
\hline $25 \%$ Scour at pier 2 & 0.04 & 0.04 & 0.23 & 0.23 & 0.79 & 0.79 & 10.9 & 10.6 & 12.3 & 12.9 & 12.5 & 14.5 & $3^{\text {rd }}$ \\
\hline $45 \%$ Scour at pier 2 & 0.06 & 0.06 & 2.05 & 2.05 & 7.23 & 7.23 & 9.67 & 11.6 & 6.57 & 8.57 & 8.04 & 10.0 & $4^{\text {th }}$ \\
\hline $25 \%$ Scour at pier 3 & 0.01 & 0.10 & 0.17 & 0.17 & 0.67 & 0.67 & 13.6 & 10.6 & 11.6 & 13.5 & 17.3 & 14.8 & $3^{\text {rd }}$ \\
\hline $45 \%$ Scour at pier 3 & 0.0 & 1.51 & 7.50 & 8.13 & 5.55 & 8.98 & 15.5 & 5.18 & 3.97 & 5.81 & 8.57 & 9.61 & $4^{\text {th }}$ \\
\hline
\end{tabular}

To quantify the severity of the scour damage (in terms of foundation stiffness loss), an indicator based on the RMS differences between the estimated mode shape amplitudes and the corresponding healthy mode shape is developed. The healthy mode shape values prior to any scour occurrence may be calculated from the physical measurements taken, or from a finite-element model of the undamaged bridge. The RMS difference is calculated as a square root of the sum of squared differences between the damaged and healthy mode shape amplitudes along the bridge:

$$
R M S=\sqrt{\sum_{x=1}^{m}\left(\varphi_{x}^{\text {Healthy }}-\varphi_{x}^{\text {Scoured }}\right)^{2}}
$$

where, $\varphi^{\text {Healthy }}$ and $\varphi^{\text {Scoured }}$ are the amplitudes of healthy and scoured mode shapes, respectively and $m$ is the total number of points in the mode shape.

To investigate the effectiveness of the RMS differences at quantifying scour damage, the RMS differences between a healthy mode shape extracted from an eigenvalue analysis in the numerical model, and the fifty mode shapes estimated for each damage condition are presented in Figure 7. The data from an eigenvalue analysis in the numerical model, and the

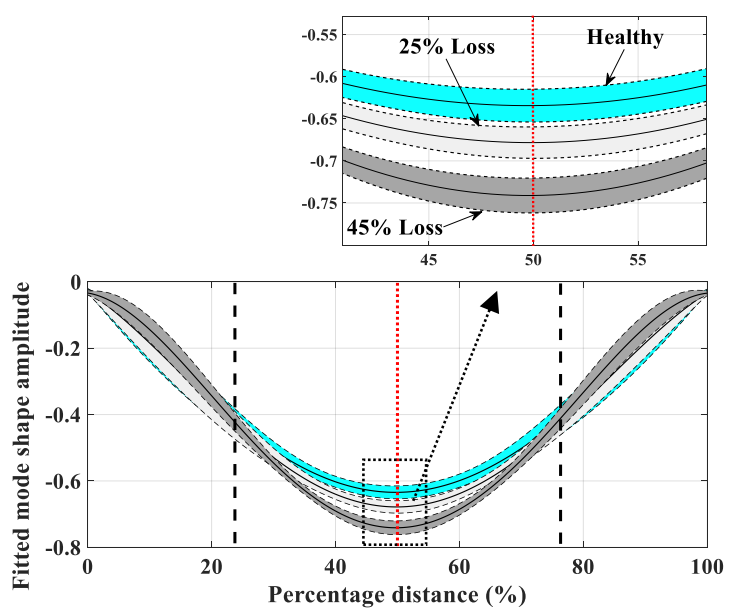

(a)

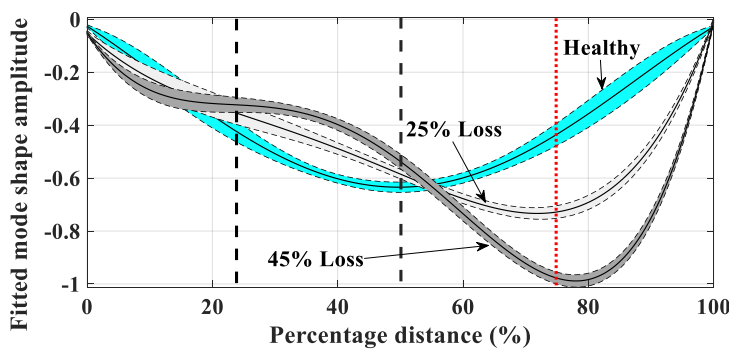

(b)

Figure $64^{\text {th }}$ degree polynomial fit of the mode shape for healthy and scoured bridge condition: (a) scour at pier 2, and (b) scour at pier 3. 
fifty mode shapes estimated for each damage condition are presented in Figure 7 . The data is presented in terms of the mean value with an error bar (mean \pm one standard deviation) showing the variability in the analysis. There is a near-linear variation in the RMS with percentage stiffness reduction with the $R^{2}$ value for the scour location at Pier 2 and 3 being 0.993 and 0.998 , respectively. It is noteworthy, however, that quantifying an actual extent of a scour hole affecting a given pier is still a challenge due to the nonlinear relationship between changes in soil $G$, and reduction in contact area should scour undermine the foundation. It should therefore be understood that the method adopted here can only infer an amount of foundation stiffness reduced due to scour occurrence. This is arguably a more useful metric than the actual scour hole magnitude as it is a direct measure of the structural distress due to scour.

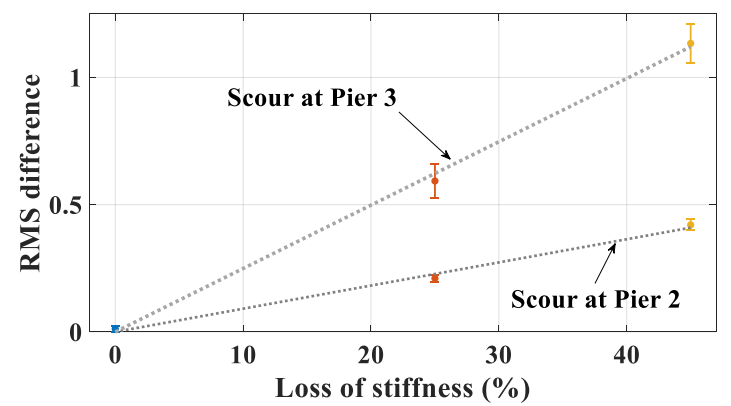

Figure 7 Root mean square differences (mean \pm one standard deviation) for healthy and damaged cases.

\section{EXPERIMENTAL ANALYSIS}

\subsection{Laboratory scale-model bridge}

Using the decentralized approach to detect scourrelated foundation stiffness loss at bridge foundations is experimentally investigated in this section. A scaled bridge model with four simplysupported spans on three-piers (see Figure 8) has been developed at Kyoto University and is used to test the approach ${ }^{6,56}$. The model piers are supported on springs to simulate the behavior of shallow foundations, and the abutments are considered as pinned. Bearing plates are used to create pinned and roller supports for each span. Four parallel springs are used at each pier to provide vertical stiffness (Figure 10), which can be reduced to simulate scour occurrence. Each spring has a stiffness of 49000 $\mathrm{N} / \mathrm{m}$ for the healthy case, providing a total stiffness of $196000 \mathrm{~N} / \mathrm{m}$ at each pier support. The spring stiffness was chosen so as to model an equivalent 4 $\mathrm{m} \times 2 \mathrm{~m}$ shallow foundation on a loose to medium dense uniform sand deposit ${ }^{6}$. The geometric and material properties of one of the bridge beams are shown in Table 5. Although the laboratory bridge is simplified relative to a real full-scale structure, it can provide a beneficial way for testing the scour damage detection approach postulated in this paper in a preliminary sense. Results from this model should therefore be considered preliminary until full-scale validations are undertaken.

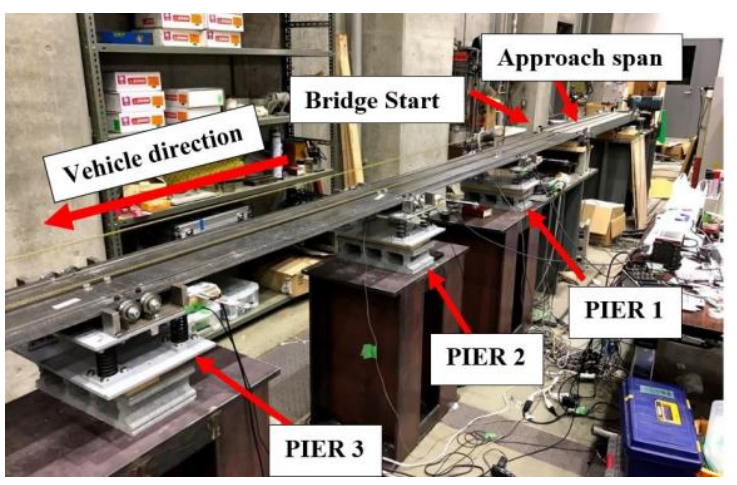

Figure 8 A scaled bridge model at Kyoto University, Japan.

Table 5

Properties of the scaled beam.

\begin{tabular}{lll}
\hline Bridge property & Notation & Value \\
\hline Span Length & $L_{S C A L E D}$ & $1.3 \mathrm{~m}$ \\
Young's & $E_{S C A L E D}$ & $205 \times 10^{3} \mathrm{~N} / \mathrm{mm}^{2}$ \\
Modulus & & \\
Density & $P$ & $7.85 \times 10^{3} \mathrm{~kg} / \mathrm{m}^{3}$ \\
Beam depth & $D_{S C A L E D}$ & $8.07 \mathrm{~mm}$ \\
Beam width & $W_{S C A L E D}$ & $300 \mathrm{~mm}$ \\
$\begin{array}{l}\text { Second moment } \\
\text { of area }\end{array}$ & $I_{S C A L E D}$ & $13.14 \times 10^{3} \mathrm{~mm}^{4}$ \\
\hline
\end{tabular}

\subsection{Vehicle model}

The model bridge is traversed by a scaled vehicle, comprising a two-axle tractor, towing a twoaxle trailer, see Figure 9. The vehicle runs on tracks attached to the bridge beams. Both tractor and trailer have a main body consisting of a sprung steel plate. The tractor front and rear axles have two suspension springs (one for each wheel) of stiffness $1533 \mathrm{~N} / \mathrm{m}$ and $1753 \mathrm{~N} / \mathrm{m}$, respectively. The trailer has four suspension springs, each of stiffness $8464 \mathrm{~N} / \mathrm{m}^{56}$.

An electronic controller is used to maintain a constant vehicle velocity while it traverses the bridge $^{56}$. For the tests in this paper, three vehicle velocities are considered, $1.14 \mathrm{~m} \mathrm{~s}^{-1}, 1.20 \mathrm{~m} \mathrm{~s}^{-1}$ and $1.26 \mathrm{~m} \mathrm{~s}^{-1}$. The trailer mass of $13.7 \mathrm{~kg}$ (of which 10.1 $\mathrm{kg}$ is sprung) is kept constant, while three different tractor masses, $24.3 \mathrm{~kg}, 25.3 \mathrm{~kg}$, and $26.3 \mathrm{~kg}$ are used 
for the tests. The sprung mass of the tractor for these three weights are $20.7 \mathrm{~kg}, 21.7 \mathrm{~kg}$, and $22.7 \mathrm{~kg}$, respectively. As a result, there are a total of nine vehicles used in the tests $(3$ tractor weights $\times 3$ velocities).

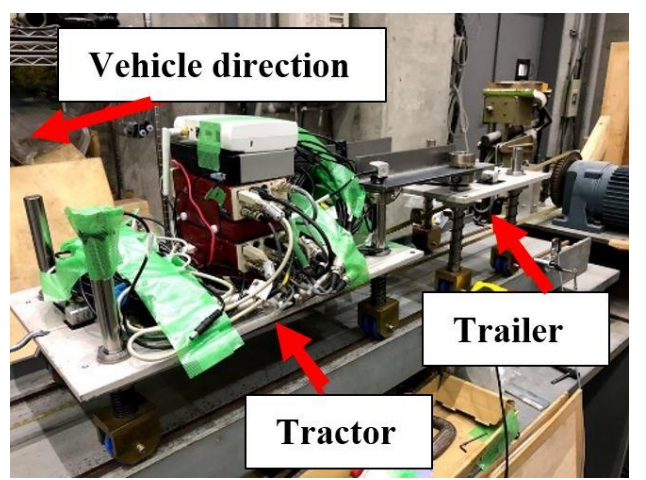

Figure 9 Vehicle model used in the experiment.

\subsection{Scour modelling and data acquisition}

Seven accelerometers are deployed on the bridge, four at the midspans and three at the pier locations (an accelerometer at Pier 2 is shown in Figure 10). To replicate a situation where only two sensors are available but re-deployable, data from only two sensors is used in any one phase of measurement. These sensors measure the vertical bridge accelerations due to the passing vehicle model. To model scour, four springs with stiffness $37000 \mathrm{~N} / \mathrm{m}$ and $27000 \mathrm{~N} / \mathrm{m}$ are used to replace the $49000 \mathrm{~N} / \mathrm{m}$ springs at the pier support, giving stiffness reductions of $24.5 \%(\approx 25 \%)$ and $44.9 \%(\approx 45 \%)$, respectively. Four scour scenarios are investigated, $25 \%$ and $45 \%$ stiffness loss at Pier 2, and $25 \%$ and $45 \%$ stiffness loss at Pier 3. For each scour case considered, each of the nine vehicle cases traverses the bridge. Hence, there are 9 healthy bridge cases and $9 \times 4$ (=36) damaged bridge cases. All 45 cases are repeated 30 times to test for repeatability.

To find a mode shape, the accelerations measured by two adjacent sensors are taken from the passage of one of the nine vehicle cases. For the chosen vehicle case, the results from one of the 30 runs is used in the procedure. The measured accelerations at the two sensor points are processed using FDD to obtain the modal amplitudes due to the given vehicle crossing at these sensor locations. One of the sensors is then considered to move to the next point on the bridge while the second sensor remains fixed, in keeping with the re-deployable sensor approach. In reality, the sensors were not moved but data was taken from one of the same sensors and one new one. A new set of accelerations is measured due to the passage of another vehicle (one of the 30 runs of one of the nine vehicles). Using FDD, the modal amplitudes at these two sensor locations are obtained. Considering the abutments as fixed and using seven locations of measurement, the process is repeated in six phases until the modal amplitudes are obtained along the entire bridge. The global mode shape is obtained by combining the mode shape segments in the same manner described in the numerical analysis previously, using the common sensor in each segment to scale the mode shape appropriately. It should be noted that due to the random nature in choosing the vehicle run to excite the bridge in the experimental tests, there are 60,480 possible ways in which the segments were generated using different vehicle combinations. This is calculated as permutations of 9 possible vehicle cases in 6 phases to generate a mode shape (9P6). This is calculated assuming that each vehicle is run only once (instead of 30 times).

The process is repeated for each of the four scour conditions, $25 \%$ and $45 \%$ at Piers 2 and 3 , respectively, to obtain damaged mode shapes. The results are described in the next section.

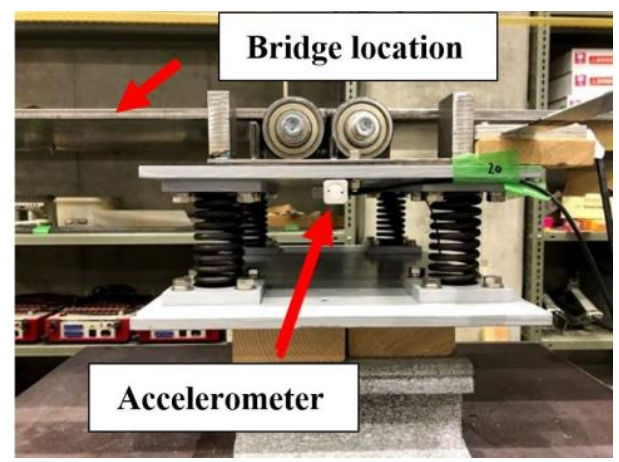

Figure 10 Pier detail and accelerometer location.

\section{ANALYSIS AND RESULTS}

The experimental mode shapes derived using the concept of re-deployable accelerometers are analyzed in this section to ascertain their performance at detecting scour-related foundation stiffness loss at the piers. While sensors were considered as being re-deployed for the purpose of the analysis in this paper, in reality this was achieved by using different sensors located at fixed points for each vehicle passage. In the actual tests, this means that data was acquired at several points along the bridge for each vehicle passage. It is therefore possible to compare the mode shape developed using re-deployed sensors with that measured directly from traditional fixed sensors along the bridge ${ }^{30}$. The 
first mode shape, derived using both approaches, are compared in Figure 11, where these are plotted as normalized to the greatest peak of the mode shape from the traditional method. The MAC value of the mode shape estimated using the re-deployable sensors is 0.9989 as compared to the traditional mode shape, suggesting that the mode shape derived using re-deployable sensors and subsequent scaling and combining provides accurate results.

Since nine vehicles were used to obtain signals along the bridge for the healthy and damaged cases, a statistical analysis of the mode shapes derived using the re-deployable sensors can be undertaken.

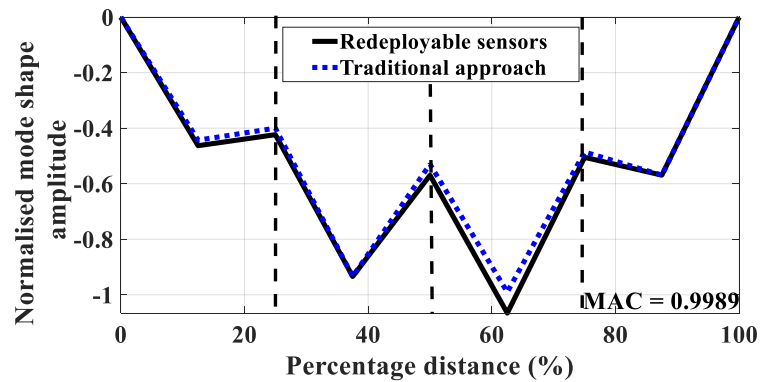

Figure 11 Comparison of Mode 1 from the proposed concept and the traditional approach.

Using the 60,480 possible combinations for a given mode shape, the mean first mode shape \pm one standard deviation, developed using the redeployable sensor technique, is presented in Figure 12.

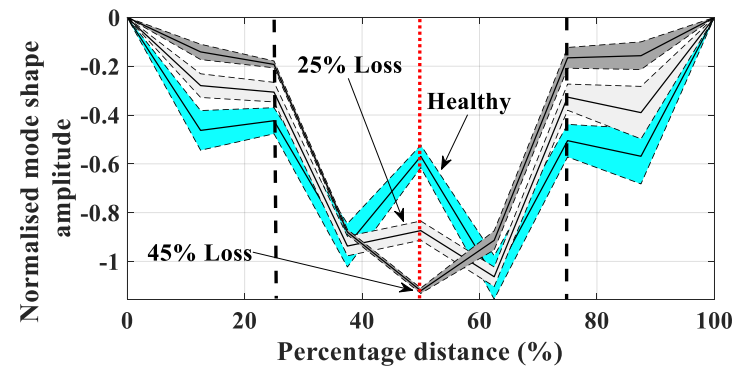

(a)

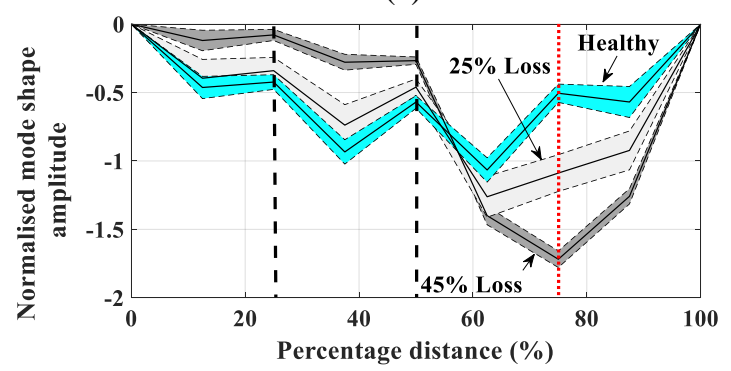

(b)

Figure 12 The first mode shape with the scour effect in the experimental analysis: (a) scour at pier 2 , and (b) scour at pier 3 .
Figure 12(a) shows the healthy case and scour at Pier 2. Figure 12(b) shows the same information for the healthy mode shape, and scour at Pier 3. There is a significant difference in the amplitude of the measured mode shape at the point of scour. It is noteworthy that the modal amplitude is also affected at unscoured piers, but the changes at the scoured pier are much greater. At the scour location, the modal amplitude decreases with loss of foundation stiffness. At the unscoured piers, the opposite effect is observed as the amplitude increases with loss of foundation stiffness. While these results are not as clean as those from the numerical study, they are consistent (see Figure 5). The method shows promise at enabling scour detection when experimental variability is present.

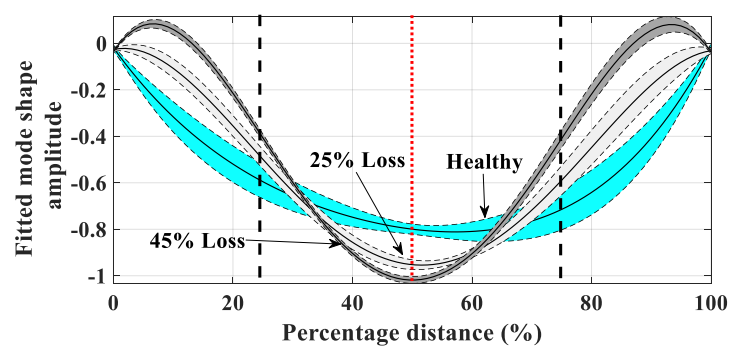

(a)

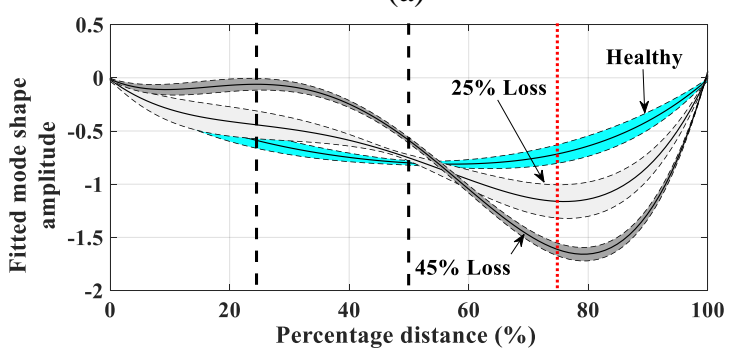

(b)

Figure $134^{\text {th }}$ degree polynomial fit of the mode shape for healthy and scoured bridge condition in the experimental analysis: (a) scour at pier 2, (b) scour at pier 3 .

As for the numerical analysis in Section 4 , a $4^{\text {th }}$ degree polynomial curve is fitted to the mode shape amplitudes and presented in Figure 13. Note that only the amplitudes at the points where sensors are deployed are used to generate the mode shapes in the figure. The purpose of this is to investigate the effectiveness of using a polynomial fit as a damage indicator to detect the location of scour. The fitted curves to the mode shapes of the healthy bridge differ significantly from those in the scoured bridge cases and follow the same trend as in the numerical analysis in Figure 6. This suggests that polynomial curve fitting to the modal amplitudes derived from 
re-deployable sensors shows promise at enabling scour to be located on a bridge. The effect of the fitted curve is to smoothen the response obtained by direct analysis of the extracted modal amplitudes, enabling an easier assessment of damage presence.

The difference in RMS values between the mean estimated healthy mode shape and scoured mode shapes are calculated as a square root of the sum of squared differences between the damaged and healthy mode shape amplitudes along the bridge. The 60,480 mode shape combinations for each scour condition are analyzed against a benchmark mean healthy mode shape (developed as the mean of the 60,480 healthy mode shape combinations). The results are shown in Figure 14. Error bars are shown on the plot to highlight the variability in the RMS values for each scour condition. A linear variation in RMS with foundation stiffness loss is evident from a trendline fitted to the data. The $\mathrm{R}^{2}$ value in case of scour location at Pier 2 and 3 is 0.992 and 0.983, respectively, suggesting a close fit. The results suggest that the RMS value may offer a way to quantify foundation stiffness loss due to scour relative to a benchmark condition (pre-scour or otherwise). While the results are from scaled experimental testing, this is a promising find.

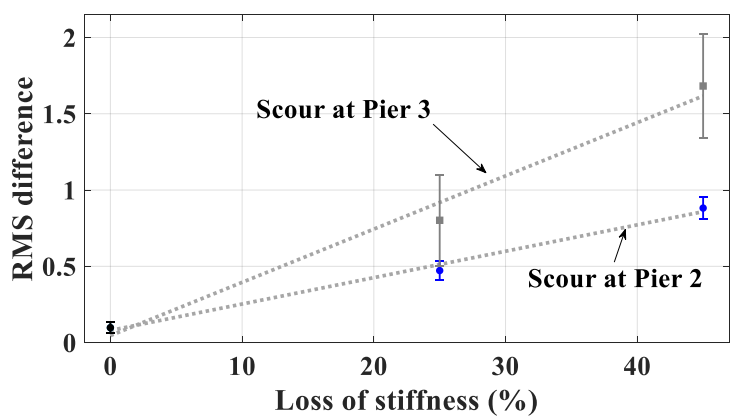

Figure 14 RMS difference (mean \pm one standard deviation) from healthy bridge, for scour at Pier 2 and 3.

\section{CONCLUSION}

This paper investigates an approach for detecting the loss in foundation stiffness of bridges resulting from scour erosion in a numerical and laboratory study using a decentralized modal analysis technique based on re-deployable accelerometers. Bridge mode shapes contain valuable information relating to their structural condition and are sensitive to global changes, in particular, changes to boundary stiffness as can occur due to scour erosion. In this paper, the mode shapes are estimated using a decentralized system of re-deployable accelerometers, whereby two accelerometers are considered to be placed sequentially at discrete points along a bridge. The modal amplitudes at sensor locations are extracted under operational conditions using output-only modal analysis with excitation from passing vehicles. The discrete mode shape segments developed along the bridge are scaled and combined together while ensuring that one sensor remains fixed as the other is moved. It is considered that the sensor re-deployment could be undertaken in the field using UAVs as part of a bridge assessment process.

Two damage indicators are proposed. The first is based on fitting polynomial curves to the discrete modal amplitudes to assist in locating scour damage, the second is based on calculating RMS differences between healthy and damaged mode shapes to quantify the foundation stiffness loss due to scour. The approach is developed in this paper and tested both numerically and using scaled experimental testing on a laboratory-scale bridge at Kyoto University. The main findings of the study are as follows:

1. In the numerical and experimental analysis, the derived mode shapes from the re-deployable sensors compare well with those extracted from the theoretical eigenvalue analysis and the traditional output-only approach. This is significant as it demonstrates that the approach is unaffected by variability in the excitation, enabling the mode-shape estimation by stitching together various mode shape segments. Furthermore, these mode shapes exhibit sensitivity to scour at two locations on a four-span representative bridge.

2. A $4^{\text {th }}$ degree polynomial fit to the modal amplitudes exhibits a reasonable change at the scour locations indicating its potential suitability as a scour damage indicator. It also has the benefit of smoothing the response of the mode shape while preserving the change at the damage location.

3. In the numerical and experimental analysis, the difference in RMS between the estimated healthy mode shapes and the scoured mode shapes is found to increase linearly with the reduction in scour-related foundation stiffness.

The results in this paper are an improvement on previous mode shape-based damage detection methods, which either rely on a high number of 
distributed sensors to calculate accurate modal data or on moving sensors such as vehicles, which tend to require very low velocities for accurate data acquisition. The analysis in this paper suggests that two sensors sequentially moved along a bridge are capable of developing an estimate of the mode shape under given scour conditions with sufficient accuracy to enable the detection of scour. Although the method was successfully tested using onedimensional numerical models and a simplified experimental arrangement, it is suggested that 3D numerical modelling and full-scale testing on a real bridge be undertaken before firm conclusions on the effectiveness of the approach be given.

\section{ACKNOWLEDGEMENTS}

The authors wish to acknowledge the FHWA's Long-Term Pavement Performance (LTPP) program for access to the WIM data and the financial support received from Science Foundation Ireland (SFI) under the US-Ireland R\&D partnership with the National Science Foundation (NSF) and Invest Northern Ireland (ID: 16/US/13277).

\section{REFERENCES}

1. Hamill L. Bridge Hydraulics, E and FN Spon. Routledge, London Khosronejad, A, S Kang, and F Sotiropoulos (2012), Experimental and computational investigation of local scour around bridge piers, Adv Water Resour. 1999; 37: 73-85.

2. Maddison B. Scour failure of bridges. Proc ICE - Forensic Eng. 2012; 165: 14.

3. Melville BW and Coleman SE. Bridge scour. Water Resources Publication, 2000.

4. Wardhana K and Hadipriono FC. Analysis of recent bridge failures in the United States. Journal of performance of constructed facilities. 2003; 17: 144-50.

5. Lagasse P, Schall J, Johnson F, Richardson E and Chang F. Stream Stability at Highway Structures: Federal Highway Administration Hydraulic Engineering Circular No. 20. Publication FHWA-IP-90-014, 1995.

6. Malekjafarian A, Kim C-W, O'Brien E, Prendergast LJ, Fitzgerald $\mathrm{P}$ and Nakajima S. Experimental demonstration of a mode shapebased scour monitoring method for multi-span bridges with shallow foundations. Journal of Bridge Engineering. 2020; 25: 04020050.

7. Prendergast LJ, Limongelli MP, Ademovic N, Anžlin A, Gavin K and Zanini M. Structural health monitoring for performance assessment of bridges under flooding and seismic actions. Structural Engineering International. 2018; 28: 296-307.
8. Giordano PF, Prendergast LJ and Limongelli M. A framework for assessing the value of information for health monitoring of scoured bridges. Journal of Civil Structural Health Monitoring. 2020; 10: 485-96.

9. Anderson NL, Ismael AM and Thitimakorn T. Ground-penetrating radar: a tool for monitoring bridge scour. Environmental and Engineering Geoscience. 2007; 13: 1-10.

10. Forde M, McCann D, Clark M, Broughton K, Fenning $\mathrm{P}$ and Brown A. Radar measurement of bridge scour. Ndt \& E International. 1999; 32: 481-92.

11. Briaud J-L, Hurlebaus S, Chang K-A, et al. Realtime monitoring of bridge scour using remote monitoring technology. Texas Transportation Institute, 2011.

12. Hunt BE. Monitoring scour critical bridges. Transportation Research Board, 2009.

13. Prendergast LJ and Gavin K. A review of bridge scour monitoring techniques. Journal of Rock Mechanics and Geotechnical Engineering. 2014; 6: 138-49.

14. Doebling SW, Farrar CR, Prime MB and Shevitz DW. Damage identification and health monitoring of structural and mechanical systems from changes in their vibration characteristics: a literature review. United States: Los Alamos National Lab., NM (United States), 1996.

15. Sohn H, Farrar CR, Hemez FM, et al. A review of structural health monitoring literature: 19962001. Los Alamos National Laboratory, USA. 2003: 1-7.

16. Bao T and Liu Z. Vibration-based bridge scour detection: a review. Structural Control and Health Monitoring. 2017; 24: e1937.

17. Prendergast LJ, Hester D, Gavin K and O'sullivan J. An investigation of the changes in the natural frequency of a pile affected by scour. Journal of Sound and Vibration. 2013; 332: 6685-702.

18. Prendergast LJ, Hester D and Gavin K. Development of a vehicle-bridge-soil dynamic interaction model for scour damage modelling. Shock and Vibration. 2016; 2016: 1-15.

19. Prendergast LJ, Hester D and Gavin K. Determining the presence of scour around bridge foundations using vehicle-induced vibrations. Journal of Bridge Engineering. 2016; 21: 04016065.

20. Prendergast LJ, Gavin K and Hester D. Isolating the location of scour-induced stiffness loss in bridges using local modal behaviour. Journal of Civil Structural Health Monitoring. 2017; 7: 483-503.

21. Malekjafarian A, Prendergast LJ and OBrien EJ. Use of mode shape ratios for pier scour monitoring in two-span integral bridges under 
changing environmental conditions. Canadian Journal of Civil Engineering. 2020; 47: 1-12.

22. Ju S-H. Determination of scoured bridge natural frequencies with soil-structure interaction. Soil Dynamics and Earthquake Engineering. 2013; 55: 247-54.

23. Kong $X$ and Cai C. Scour effect on bridge and vehicle responses under bridge-vehicle-wave interaction. Journal of Bridge Engineering. 2016; 21: 04015083.

24. Bao T, Swartz RA, Vitton S, Sun Y, Zhang C and Liu Z. Critical insights for advanced bridge scour detection using the natural frequency. Journal of Sound and Vibration. 2017; 386: 116-33.

25. Li Q, Prendergast LJ, Askarinejad A, Chortis G and Gavin K. Centrifuge Modeling of the Impact of Local and Global Scour Erosion on the Monotonic Lateral Response of a Monopile in Sand. Geotechnical Testing Journal. 2020; 43.

26. Chen C-C, Wu W-H, Shih F and Wang S-W. Scour evaluation for foundation of a cablestayed bridge based on ambient vibration measurements of superstructure. NDT \& E International. 2014; 66: 16-27.

27. Xiong W, Kong B, Tang P and Ye J. Vibrationbased identification for the presence of scouring of cable-stayed bridges. Journal of Aerospace Engineering. 2018; 31: 04018007.

28. Elsaid A and Seracino R. Rapid assessment of foundation scour using the dynamic features of bridge superstructure. Construction and Building Materials. 2014; 50: 42-9.

29. Foti S and Sabia D. Influence of foundation scour on the dynamic response of an existing bridge. Journal of bridge engineering. 2011; 16 : 295-304

30. Kim J-T, Ryu Y-S, Cho H-M and Stubbs N. Damage identification in beam-type structures: frequency-based method vs mode-shape-based method. Engineering structures. 2003; 25: 5767.

31. Ewins DJ. Modal testing: theory and practice. Research studies press Letchworth, 1984.

32. Carden EP and Fanning P. Vibration based condition monitoring: a review. Structural health monitoring. 2004; 3: 355-77.

33. Zhang $\mathrm{L}$ and Brincker R. An overview of operational modal analysis: major development and issues. 1st international operational modal analysis conference. Aalborg Universitet, 2005, p. 179-90.

34. Gao Y, Spencer Jr B and Ruiz-Sandoval M. Distributed computing strategy for structural health monitoring. Structural Control and Health Monitoring: The Official Journal of the International Association for Structural Control and Monitoring and of the European
Association for the Control of Structures. 2006; 13: 488-507.

35. Gao Y and Spencer Jr BF. Structural health monitoring strategies for smart sensor networks. Newmark Structural Engineering Laboratory. University of Illinois at Urbana ..., 2008.

36. Hoskere V, Park J-W, Yoon H and Spencer Jr BF. Vision-based modal survey of civil infrastructure using unmanned aerial vehicles. Journal of Structural Engineering. 2019; 145: 04019062.

37. Nagayama T, Spencer Jr B and Rice JA. Autonomous decentralized structural health monitoring using smart sensors. Structural Control and Health Monitoring: The Official Journal of the International Association for Structural Control and Monitoring and of the European Association for the Control of Structures. 2009; 16: 842-59.

38. Sim S-H, Carbonell-Márquez JF, Spencer Jr B and Jo $\mathrm{H}$. Decentralized random decrement technique for efficient data aggregation and system identification in wireless smart sensor networks. Probabilistic Engineering Mechanics. 2011; 26: 81-91.

39. Sim S-H, Spencer Jr B, Zhang M and Xie H. Automated decentralized modal analysis using smart sensors. Structural Control and Health Monitoring. 2010; 17: 872-94.

40. Spencer Jr BF, Hoskere V and Narazaki Y. Advances in computer vision-based civil infrastructure inspection and monitoring. Engineering. 2019; 5: 199-222.

41. Döhler M and Mevel L. Modular subspacebased system identification from multi-setup measurements. IEEE Transactions on Automatic Control. 2012; 57: 2951-6.

42. Döhler M, Lam X-B and Mevel L. Uncertainty quantification for modal parameters from stochastic subspace identification on multisetup measurements. Mechanical Systems and Signal Processing. 2013; 36: 562-81.

43. OBrien EJ, Fitzgerald PC, Malekjafarian A and Sevillano E. Bridge damage detection using vehicle axle-force information. Engineering Structures. 2017; 153: 71-80.

44. Fitzgerald PC, Malekjafarian A, Cantero D, OBrien EJ and Prendergast LJ. Drive-by scour monitoring of railway bridges using a waveletbased approach. Engineering Structures. 2019; 191: 1-11.

45. Elhattab A, Uddin N and OBrien E. Drive-by bridge frequency identification under operational roadway speeds employing frequency independent underdamped pinning stochastic resonance (fi-upsr). Sensors. 2018; 18: 4207.

46. Mei Q, Gül M and Boay M. Indirect health monitoring of bridges using Mel-frequency cepstral coefficients and principal component 
analysis. Mechanical Systems and Signal Processing. 2019; 119: 523-46.

47. Malekjafarian A, McGetrick PJ and OBrien EJ. A Review of Indirect Bridge Monitoring Using Passing Vehicles. Shock and Vibration. 2015; 2015: 16.

48. Keenahan J, OBrien EJ, McGetrick PJ and Gonzalez A. The use of a dynamic truck-trailer drive-by system to monitor bridge damping. Structural Health Monitoring. 2014; 13: 14357.

49. Fukuhara T. Apparatus mounted on vehicles for detecting road surface conditions. Google Patents, 1987.

50. McGetrick PJ, Gonzlez A and OBrien EJ. Theoretical investigation of the use of a moving vehicle to identify bridge dynamic parameters. Insight-Non-Destructive Testing and Condition Monitoring. 2009; 51: 433-8.

51. Malekjafarian A and OBrien EJ. On the use of a passing vehicle for the estimation of bridge mode shapes. Journal of Sound and Vibration. 2017; 397: 77-91.

52. Malekjafarian A and OBrien EJ. Identification of bridge mode shapes using short time frequency domain decomposition of the responses measured in a passing vehicle. Engineering Structures. 2014; 81: 386-97.

53. Brincker R, Zhang L and Andersen P. Modal identification of output-only systems using frequency domain decomposition. Smart materials and structures. 2001; 10: 441.

54. Cantero D, O'Brien EJ and González A. Modelling the vehicle in vehicleinfrastructure dynamic interaction studies. Proceedings of the Institution of Mechanical Engineers, Part K: Journal of Multi-body Dynamics. 2010; 224: 243-8.

55. González A. Vehicle-bridge dynamic interaction using finite element modelling. Finite element analysis. InTech, 2010, p. 63762.

56. Fitzgerald PC, Malekjafarian A, Bhowmik B, et al. Scour damage detection and structural health monitoring of a laboratory-scaled bridge using a vibration energy harvesting device. Sensors. 2019; 19: 2572.

57. Tyan F, Hong Y-F, Tu S-H and Jeng WS. Generation of random road profiles. Journal of Advanced Engineering. 2009; 4: 1373-8.

58. Kwon YW and Bang $\mathrm{H}$. The finite element method using MATLAB. CRC press, 2018.

59. Prendergast LJ and Gavin K. A comparison of initial stiffness formulations for small-strain soil-pile dynamic Winkler modelling. Soil Dynamics and Earthquake Engineering. 2016; 81: 27-41.

60. FEMA P. commentary for the seismic rehabilitation of buildings (FEMA356).
Washington, DC: Federal Emergency Management Agency. 2000; 7.

61. Pais A and Kausel E. Approximate formulas for dynamic stiffnesses of rigid foundations. Soil Dynamics and Earthquake Engineering. 1988; 7: 213-27.

62. Mylonakis G, Nikolaou S and Gazetas G. Footings under seismic loading: Analysis and design issues with emphasis on bridge foundations. Soil Dynamics and Earthquake Engineering. 2006; 26: 824-53.

63. ISO. Mechanical vibration-Road surface profiles-Reporting of measured data. 1995.

64. Cebon D. Handbook of vehicle-road interaction. The Netherlands: Swets and Zeitlinger, Lisse, 1999.

65. Walker D and Cebon D. The metamorphosis of LTPP traffic data. 6th International Conference on Weigh-In-Motion (ICWIM 6) International Society for Weigh-In-Motion. Dallas, United States2012.

66. Walker D, Selezneva O and Wolf D. Findings from LTPP SPS WIM systems validation study. 6th International Conference on Weigh-InMotion (ICWIM 6) International Society for Weigh-In-Motion. Dallas, United States2012.

67. Tedesco J, McDougal WG and Ross CA. Structural dynamics. Pearson Education, 2000.

68. Warburton GB. Dynamics of structures, by Ray W. Clough and Joseph Penzien, 2nd edition, McGraw-Hill, New York, 1993. No. of pages: 738. ISBN 0-07-011394-7. Earthquake Engineering \& Structural Dynamics. 1995; 24: 457-62.

69. Oztoprak S and Bolton M. Stiffness of sands through a laboratory test database. Géotechnique. 2013; 63: 54-70.

70. Klinga JV and Alipour A. Assessment of structural integrity of bridges under extreme scour conditions. Engineering Structures. 2015; 82: 55-71.

71. Prendergast LJ, Reale $\mathrm{C}$ and Gavin K. Probabilistic examination of the change in eigenfrequencies of an offshore wind turbine under progressive scour incorporating soil spatial variability. Marine Structures. 2018; 57: 87-104.

72. Vandekerckhove J, Matzke D and Wagenmakers E-J. Model comparison and the principle of parsimony. Oxford handbook of computational and mathematical psychology. 2015: 300-19.

73. Myung IJ. Tutorial on maximum likelihood estimation. Journal of mathematical Psychology. 2003; 47: 90-100.

74. Akaike H. A new look at the statistical model identification. IEEE transactions on automatic control. 1974; 19: 716-23. 